OPEN ACCESS

Edited by: Ilgin Özden,

Masaka Hospital, Uganda

Reviewed by:

Ivone Malla,

Hospital Universitario

Austral, Argentina

Orkan Ergün,

Ege University, Turkey

*Correspondence:

Liying Dai

dailiying200@sina.com

${ }^{\dagger}$ These authors have contributed equally to this work

Specialty section: This article was submitted to

Neonatology,

a section of the journal

Frontiers in Pediatrics

Received: 01 October 2021 Accepted: 29 October 2021 Published: 01 December 2021

Citation:

Wang Y, Wang S, Wang L, Bi S, Zhang J, Zha P and Dai L (2021) Transarterial Embolization in Neonatal Kasabach-Merritt Syndrome.

Front. Pediatr. 9:788120.

doi: $10.3389 /$ fped.2021.788120

\section{Transarterial Embolization in Neonatal Kasabach-Merritt Syndrome}

\author{
Yinghao Wang ${ }^{1 \dagger}$, Song Wang ${ }^{2 \dagger}$, Lili Wang ${ }^{1}$, Shaohua $\mathrm{Bi}^{1}$, Jian Zhang ${ }^{1}$, Ping Zha ${ }^{1}$ and \\ Liying Dai ${ }^{1 *}$
}

${ }^{1}$ Department of Neonatology, Anhui Provincial Children's Hospital, Anhui Medical University, Hefei, China, ${ }^{2}$ Department of Radiology, Anhui Provincial Children's Hospital, Anhui Medical University, Hefei, China

Background: Kasabach-Merritt syndrome (KMS) is characterized by large hemangiomas and persistent thrombocytopenia, which may result in visceral hemorrhage and disseminated intravascular coagulation. This study aimed to evaluate the value of transarterial embolization (TAE) in neonatal KMS patients.

Patients and Methods: The clinical course of 11 neonates with KMS who underwent TAE in the Department of Neonatology, Anhui Provincal Children's Hospital, Anhui Medical University, China, were reviewed retrospectively.

Results: Eleven neonates with KMS (nine male and two female) were admitted to our hospital between the age of $1 \mathrm{~h}$ and 6 days. All were born with progressively enlarged hemangiomas and persistent thrombocytopenia. The largest lesion had its maximum size reached at $15 \times 8 \times 8 \mathrm{~cm}$. Eight patients had cutaneous hemangiomas (1 right face, one oropharynx, one left upper arm, two back, one left lumbar, one right lower leg, and one right thigh), and three patients had liver hemangiomas. All 11 patients underwent TAE. Nine patients underwent two TAEs, and two patients underwent only one embolization procedure. They all obtained $>80 \%$ devascularization of their lesions without a major complication. The platelet count increased at 2-5 days after treatment and reached normal count and coagulation profile at 18-28 days after the TAE.

Conclusions: TAE is a safe and effective alternative therapy for neonatal KMS patients.

Keywords: neonate, transarterial embolization (TAE), Kasabach-Merrit syndrome, bleomycin, hemangioma

\section{INTRODUCTION}

The Kasabach-Merritt syndrome (KMS), also known as giant hemangioma-thrombocytopenia syndrome, was first reported by Kasabach and Merritt in 1940 (1). In 1997, Sarkar revised the KMS to Kasabach-Merritt phenomenon (2). Approximately $80 \%$ of all KMS occur within 1 year of birth, with fatality rates ranging between 10 and $37 \%$ (3). It is characterized by large hemangiomas, persistent thrombocytopenia, and bleeding tendency, causing joint and limb dysfunction and potentially leading to serious visceral bleeding and disseminated intravascular coagulation (DIC) (4). Glucocorticoids, sirolimus, or propranolol is most commonly used to treat KMS (5). However, the long treatment course and high rate of side effects prompt us into seeking other therapeutic alternatives (6-8). Transarterial embolization (TAE) has been introduced to manage KMS for about 20 years, 
with decent results in experienced hands $(9,10)$. We have previously analyzed the clinical features of 16 neonates with KMS and found that TAE had a good effect in some neonates (11). In this report, we reviewed our own experience of KMS treated with TAE.

\section{MATERIALS AND METHODS}

This study protocol was approved by the ethics committee of Anhui Provincial Children's Hospital, Anhui Medical University, and informed consent was obtained from the parents. We conducted a retrospective chart view of neonates diagnosed with KMS and who were admitted between January 2016 and June 2021. Eleven cases were identified with (1) platelet count $<50 \times 10^{9} / \mathrm{L}$ and (2) treated by TAE. The sex, age of onset, location and volume of the lesion, laboratory results, image findings, treatment methods, and outcome were retrieved from the electronic medical records.

\section{Treatment Methods}

The medical therapy included glucocorticoids (prednisolone, $2 \mathrm{mg} / \mathrm{kg} / \mathrm{day} ;$ methylprednisolone, $2 \mathrm{mg} / \mathrm{kg} /$ day; or dexamethasone, $1 \mathrm{mg} / \mathrm{kg} / \mathrm{day})$, propranolol (1.5-2 mg/kg/12 h), and sirolimus $(0.025 \mathrm{mg} / \mathrm{kg} /$ day $)$.

The femoral artery was cannulated under general anesthesia using the Seldinger technique. A 4-F femoral artery sheath was placed to establish the arterial access, followed by heparinization. Selective arteriography of the lesion using a Cobra-2 catheter (Terumo Corporation, Tokyo, Japan) was performed to identify the feeding artery of the hemangioma. A 2.7-F Progreat catheter (Terumo Corporation, Tokyo, Japan) was then used to catheterize the main feeding artery directly. A mixture of bleomycin $\left(8-10 \mathrm{mg} / \mathrm{m}^{2}\right)$, lipiodol (2 $\left.\mathrm{ml}\right)$, dexamethasone (1 $\left.\mathrm{mg}\right)$, and contrast agents, was injected into the main feeding artery until lipiodol was evenly distributed in the lesion. Polyvinyl alcohol (PVA) will be given directly to the feeding artery if the blood flow velocity in the feeding artery remained high. The size of the PVA particles was selected according to the filling time of the hemangioma. PVA particles, $300-500 \mu \mathrm{m}$ in diameter or 500$700 \mu \mathrm{m}$ in diameter, were used when the filling time was 2 to $3 \mathrm{~s}$ or $>3$ seconds, respectively. No PVA particles were given with filling time of $<2 \mathrm{~s}$. Patients with active bleeding or platelet count $<20 \times 10^{9} / \mathrm{L}$ received platelet infusions, and patients with DIC were treated with cryoprecipitate or prothrombin complex before and after the TAE.

\section{Therapeutic Assessment}

The procedure was considered technically successful if $>80 \%$ of the tumor vasculature was occluded (10). The hemangioma volume, platelet count, and coagulation function were measured 4 weeks after TAE. The efficacy of TAE was assessed based on two factors: (1) the reduction in tumor volume was estimated via ultrasonography using the following formula: width $\times$ depth $\times$ height $\times \pi / 6$ (width $\times$ depth $\times$ height $\times 0.52$ ), based on the shape of the lesion (12), and (2) the platelet count was increased to $>50 \times 10^{9} / \mathrm{L}$, and the coagulation function returned to normal.

\section{Data Analysis and Statistics}

SPSS version 20.0 (IBM Corporation, Chicago, Illinois) for Windows (Microsoft Corporation, Redmond, Washington) was used for statistical analyses. All statistics were tested to be of normal distribution. Data are shown as mean \pm standard deviation $(\mathrm{m} \pm \mathrm{SD})$, median (interquartile range) [M (p25, P75)], or relative percentages. A paired $t$-test was used for continuous data. Statistical significance was defined as $p<0.05$.

\section{RESULTS}

\section{Characteristics of the Patients}

The clinical data of nine male and two female patients are shown in Table 1. Their age of admission ranged from $1 \mathrm{~h}$ to 6 days. They were 10 term infants and one preterm infant, with gestational age of $38.4 \pm 1.1$ weeks and birth weight of 3,267 $\pm 341 \mathrm{~g}$.

\section{Clinical Presentation}

The lesion size all increased with time, with the largest size reaching $15.0 \times 8.0 \times 8.0 \mathrm{~cm}$; eight had cutaneous hemangiomas (one right face, one oropharynx, one left upper arm, two back, one left lumbar, one right lower leg, and one right thigh), and three had liver hemangiomas. The cutaneous hemangiomas presented as purple to dark red lesions. The skin of the tumor was different from the surrounding area, with obvious swelling, tension, slightly elevated but ill-defined margins, and induration (see Figure 1A). CT showed that the lesion was a large soft tissue mass, contrast-enhanced CT showed obvious arterial phase enhancement inside the mass, and computed tomography-angiography (CTA) showed an abundant tumor blood supply (see Figures 1C-E). In the three patients with liver hemangiomas, ultrasonography showed a hyperechoic solid lesion in liver. The CT showed that the lesion was a large soft tissue mass. Contrast-enhanced CT showed obvious arterial phase enhancement inside the mass. CTA showed an abundant tumor blood supply, and chest Xray showed enlargement of the heart shadow after admission (see Figures 2A-E). One patient with enlarged cardiac silhouette soon developed heart failure. The condition of all 11 patients was complicated with diffuse ecchymosis and poor response to medical treatment.

\section{Laboratory Findings}

Thrombocytopenia and coagulation dysfunction were observed in all patients. Laboratory examinations showed the platelet count of $20.0(8.0,30.0) \times 10^{9} / \mathrm{L}$. The prothrombin time (PT) was $19.3 \mathrm{~s}(14.8,120.0)$, with a prolonged PT in six patients. The activated partial thromboplastin time (APTT) was $51.2 \mathrm{~s}$ (39.4, 86.1), with a prolonged APTT in six patients. The fibrinogen level was $0.4 \mathrm{~g} / \mathrm{L}(0.4,1.0)$, with a low fibrinogen level in all 11 patients. The D-dimer level was $37.0 \mathrm{mg} / \mathrm{L}(28.0,80.0)$, and all values were abnormally increased.

\section{Treatment and Assessment}

The initial therapy was supportive after admission. Five patients with a platelet count of $<20 \times 10^{9} / \mathrm{L}$ received apheresis 
TABLE 1 | Clinical characteristics upon admission.

\begin{tabular}{|c|c|c|c|c|c|c|c|c|c|}
\hline Case & Sex & $\begin{array}{l}\text { Age } \\
\text { (h) }\end{array}$ & Location & Lesion volume & $\begin{array}{l}\text { Platelet count } \\
\qquad\left(\times 10^{9} / \mathrm{L}\right)\end{array}$ & $\begin{array}{l}\text { PT } \\
\text { (s) }\end{array}$ & $\begin{array}{c}\text { APTT } \\
\text { (s) }\end{array}$ & $\begin{array}{c}\text { Fibrinogen } \\
\text { (g/L) }\end{array}$ & $\begin{array}{l}\text { D-dimer } \\
\text { (mg/L) }\end{array}$ \\
\hline 1 & M & 16 & Back & $8.4 \times 7.4 \times 5.3$ & 8.0 & 15.5 & 51.2 & 0.6 & 31.0 \\
\hline 2 & $\mathrm{~F}$ & 24 & Right lower leg & $6.9 \times 4.7 \times 2.3$ & 31.0 & 12.2 & 36.2 & 0.9 & 97.5 \\
\hline 3 & $\mathrm{M}$ & 1 & Left upper arm & $15.0 \times 8.0 \times 8.0$ & 20.0 & 120.0 & 86.1 & 0.3 & 80.0 \\
\hline 4 & $\mathrm{M}$ & 48 & Oropharynx & $5.1 \times 4.9 \times 3.8$ & 13.0 & 120.0 & 69.6 & 0.4 & 35.2 \\
\hline 5 & $\mathrm{M}$ & 72 & Liver & $10.2 \times 6.8 \times 5.6$ & 30.0 & 14.8 & 64.6 & 1.4 & 28.0 \\
\hline 6 & M & 100 & Liver & $7.0 \times 4.9 \times 7.0$ & 25.0 & 120.0 & 180.0 & 0.4 & 23.0 \\
\hline 7 & $\mathrm{M}$ & 6 & Liver & $6.0 \times 4.0 \times 4.0$ & 4.0 & 120.0 & 180.0 & 0.4 & 37.0 \\
\hline 8 & $\mathrm{~F}$ & 144 & Right face & $7.0 \times 6.0 \times 3.0$ & 39.0 & 15.8 & 42.0 & 0.3 & 44.0 \\
\hline 9 & $\mathrm{M}$ & 72 & Right thigh & $8.0 \times 4.0 \times 4.0$ & 10.0 & 20.5 & 50.6 & 1.3 & 80.0 \\
\hline 10 & M & 48 & Left lumbar & $5.4 \times 4.0 \times 2.6$ & 20.0 & 14.0 & 39.4 & 1.0 & 28.0 \\
\hline 11 & M & 10 & Back & $10.5 \times 10.2 \times 6.4$ & 4.0 & 19.3 & 35.4 & 0.4 & 40.2 \\
\hline
\end{tabular}

M, male; F, female; PT, prothrombin time; APTT, activated partial thromboplastin time.

platelet transfusion. Seven patients with a fibrinogen level of $<0.6 \mathrm{~g} / \mathrm{L}$ received cryoprecipitate infusions. All 11 patients received glucocorticoid treatment prior to TAE. After 3-10 days of treatment, the platelet count remained low, and the hemangioma volume failed to decrease, with hemangiomas that kept on growing in size for five cases. Four patients continued to be treated with propranolol, and two patients continued to be treated with sirolimus and maintained the serum levels between 8 and $15 \mathrm{ng} / \mathrm{ml}$, but their condition remained unimproved. All 11 patients then underwent TAE. Nine patients underwent two embolizations, and two patients underwent only one embolization. Embolization with $>80 \%$ tumor devascularization was technically successful in all 11 patients without a major complication (see Figures 1F, 2F). The platelet count started to increase $2-5$ days after treatment, reaching a normal value at 18-28 days later, by which time the coagulation function had also returned to normal. The platelet count increased from $20.0 \times 10^{9} / \mathrm{L}(8.0,30.0)$ before treatment to $255.0 \times 10^{9} / \mathrm{L}(200.0,280.0)$ weeks after treatment $(p<0.001$, see Table 2). The hemangioma size was $50.2 \pm 5.3 \%$ smaller 4 weeks after TAE, and the maximal diameter significantly decreased from $8.1 \pm 2.9 \mathrm{~cm}$ before treatment to $6.3 \pm 2.8 \mathrm{~cm}$ $(p<0.001$, see Table 2). An almost complete involution of the tumor was observed in case 8 at the 5-month follow-up visit (see Figure 1B).

\section{DISCUSSION}

KMS is a rare condition that results in vascular tumors in infants and is associated with Kaposi hemangioendothelioma and tufted hemangioma in over $70 \%$ of cases (5). KMS occurs most frequently in neonates and infants, with approximately $80 \%$ of cases occurring within 1 year after birth (3). All our cases were diagnosed within 1 week of life. KMS is characterized by life-threatening thrombocytopenia. It is believed that thrombocytopenia is due to trapping by the hemangioma and activation and aggregation of platelets and reduced fibrinogen levels $(5,13)$. High cardiac output congestive heart failure, which can significantly complicate the clinical management, occurs in one of our cases.

Medical treatment is always the initial management for KMS (5). Our patients were first treated with glucocorticoids, propranolol, or sirolimus, but the effect was poor. The severity of KMS is proportional to the hemangioma volume, with the greater the volume the more platelet consumption. Liver and retroperitoneal hemangiomas tend to have serious complications, such as heart failure secondary to increased venous return or high cardiac preload that can lead to congestive heart failure (14), and aggressive intervention is warranted. The surgical resection of KMS is not recommended due to the technical difficulty and high risk of intraoperative bleeding, postoperative infection, and extensive scarring, so surgical resection is not the first choice for liver hemangiomas (15) and also not applicable to head and face hemangiomas (12). TAE has been used in the treatment of vascular tumors for many years, with the advantages of minimal trauma, safety and reliability, and quick postoperative recovery by reducing the blood supply to the hemangioma, attenuating heart failure, and effectively promoting the regression of the hemangioma $(9,10,12)$.

KMS patients with large tumors or tumors located in the liver and have severe thrombocytopenia can undergo TAE, which was first reported by Yamamoto et al. (16). In our hospital, TAE, using bleomycin and PVA as sclerosing agents, has been routinely used for treating hemangiomas (12). Bleomycin shrinks hemangioma through multiple mechanisms, such as suppressing the metabolism of tumor cells by directly degrading DNA, which then accelerates tumor cell necrosis (17), destroying endothelial cells by the formation of microthrombi in hemangioma sinuses, leading to atrophy and fibrosis of the hemangioma (18) and obliterating the vascular lumen by activating the mTOR pathway and inducing non-specific inflammatory processes around the hemangioma (19). Embolization with PVA exerts a permanent embolic effect by adhering to the vascular wall and inducing an inflammatory cascade with angionecrosis (20). All our 11 patients underwent TAE with $>80 \%$ tumor devascularization and without major complications. The size of hemangioma decreased 


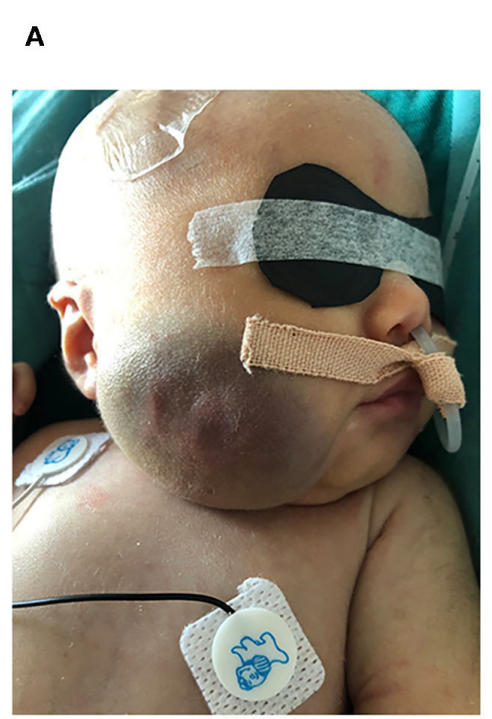

D

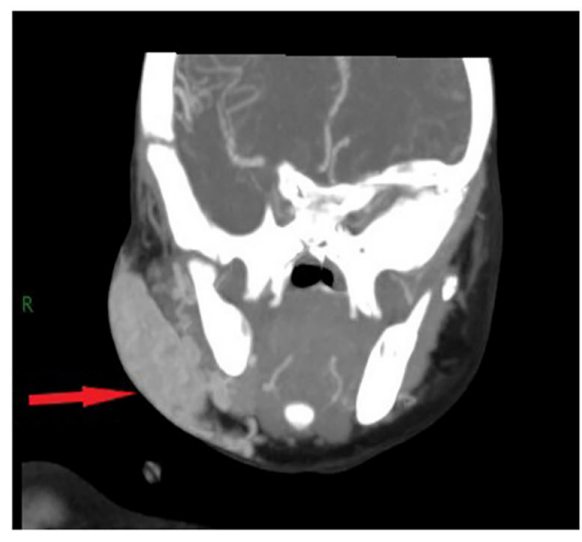

B

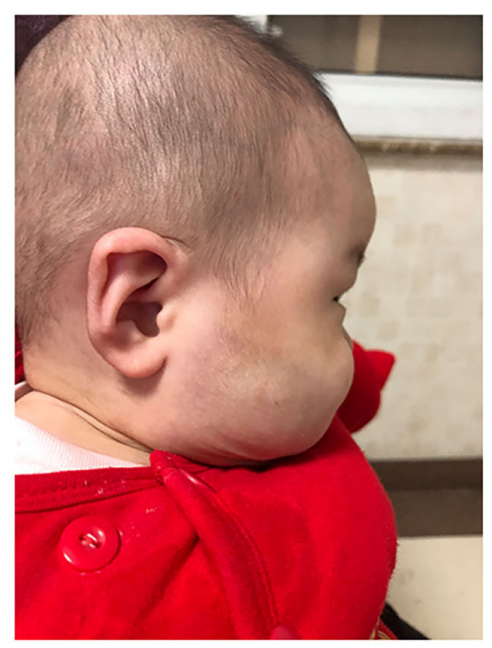

E
C

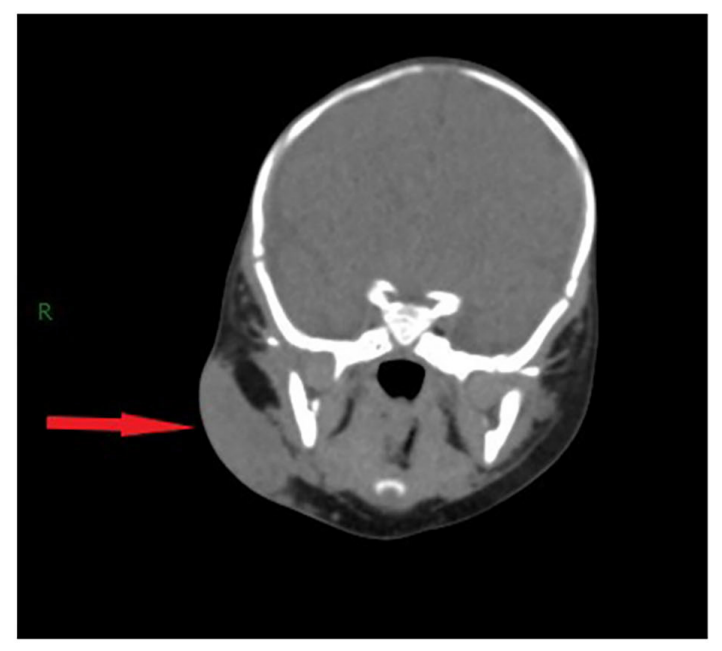

F
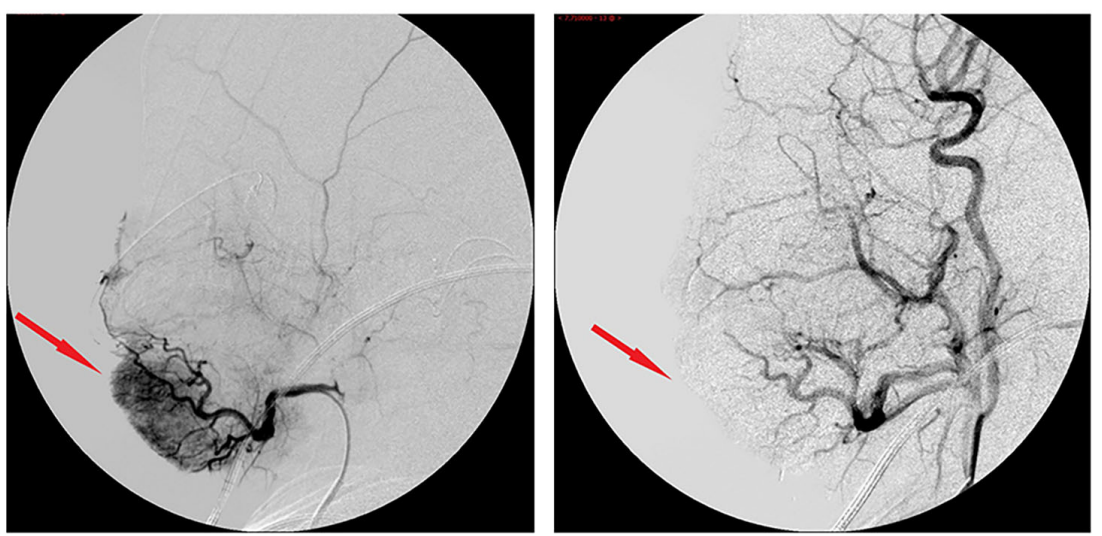

FIGURE 1 | Images from case 8 before and after TAE. (A) A large tumor that measured $7.0 \times 6.0 \times 3.0 \mathrm{~cm}$ was seen on the right face. The skin of the tumor was different from the surrounding area, with purple or dark color, obvious swelling, increased tension, slightly elevated but with ill-defined margins, and induration. (B) At 5 months after TAE, the tumor almost involuted completely. (C) CT showed that the lesion was a large soft tissue mass. (D) Contrast-enhanced CT showed obvious arterial phase enhancement inside the mass. (E) CTA showed an abundant tumor blood supply before embolization. (F) After TAE, more than $80 \%$ of the tumor-feeding arteries were embolized. CTA, computed tomography-angiography; TAE, transarterial embolization. The red arrow indicates the lesion.

approximately $50 \%$ at 4 weeks after TAE, with normalization of platelet count and coagulation function. One patient showed a dramatic response with complete disappearance of the tumor in 5 months.

The limitation of embolization is its technical difficulty in young patients. Improper embolization may cause fever, deep tissue necrosis, and scarring and could even be complicated with sepsis. In our study, two patients who underwent one embolization procedure developed a low fever. High doses of bleomycin may damage the alveolar capillaries in neonates and lead to pulmonary fibrosis in severe cases (21), so the dose of a single injection should not exceed $450 \mathrm{mg}$ (22). In sclerosing embolization, attention must be paid to prevent the regurgitation of the embolization agent, which may cause ectopic embolism and other severe unexpected complications. Successfully locating the main feeding artery to the hemangioma is the key for success (12). It is worth mentioning that activated platelets can increase the hemangioma volume by inducing coagulation, resulting in an increased ability of the hemangioma to capture and consume even more platelets, leading, in turn, to an increased risk of bleeding. Since repeated platelet infusions will cause hemangioma to grow, it is recommended that platelet transfusion is suitable only for patients with either platelet count $<20 \times$ $10^{9} / \mathrm{L}$ with a bleeding tendency or prior to invasive procedures. In our case series, the D-dimer level in four patients was high, up to $97.5 \mathrm{ng} / \mathrm{L}$, while the platelet count decreased before the treatment, but both returned to normal after treatment. The relationship between D-dimer level and the severity of KMS or the platelet count cannot be determined in our cases due to the limited sample size. The long-term outcome of TEA in neonatal 
A

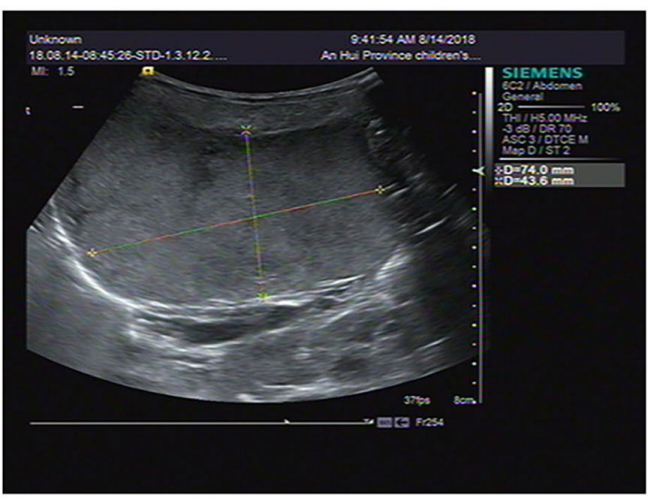

D

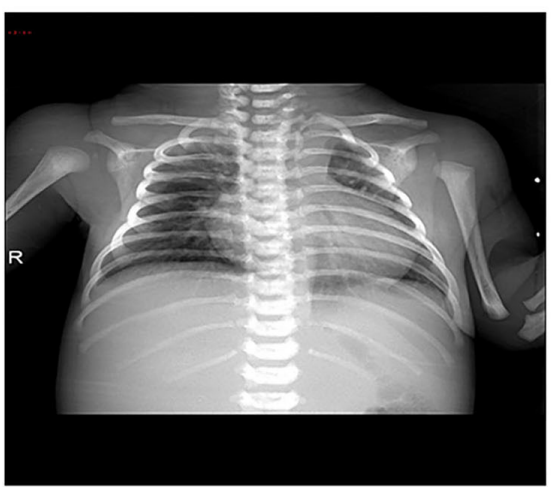

B

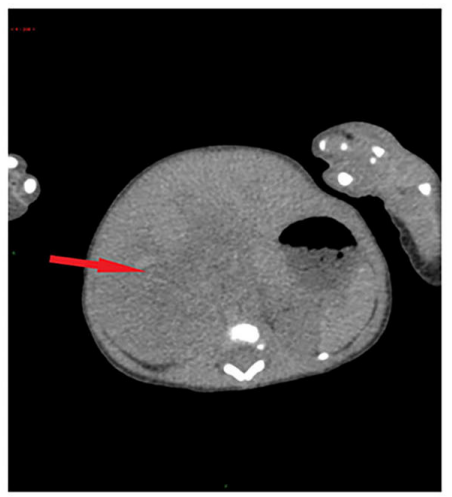

E

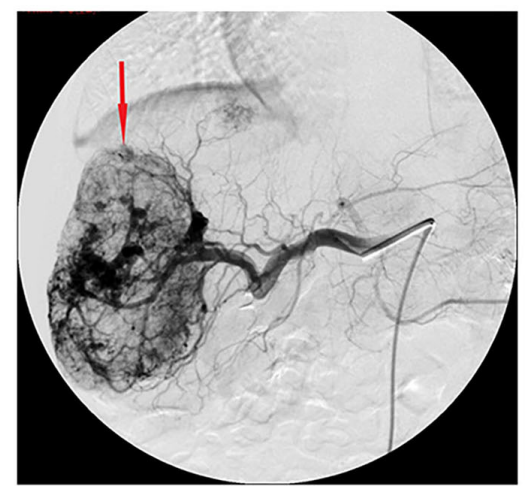

C

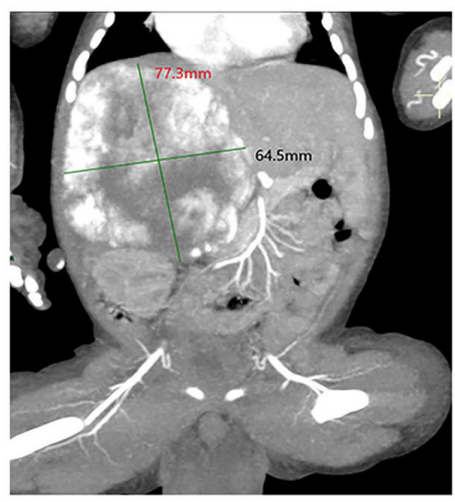

$\mathrm{F}$

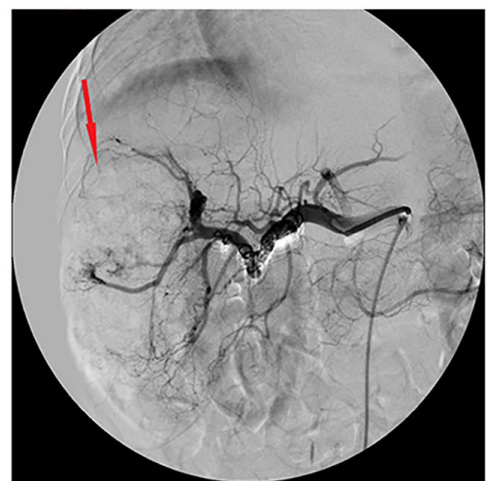

FIGURE 2 | Imaging of the hepatic hemangioma for case 6. (A) Ultrasonography showed a hyperechoic solid lesion in the liver. (B) CT showed that the lesion was a large soft tissue mass. (C) Contrast-enhanced CT showed obvious arterial phase enhancement inside the mass. (D) CXR showed enlargement of the heart shadow. (E) CTA showed an abundant tumor blood supply before embolization. (F) After TAE, more than 80\% of the tumor-feeding arteries were embolized. TAE, transarterial embolization; CTA, computed tomography-angiography; CXR, chest X-ray. The red arrow indicates the lesion.

TABLE 2 | Hemangioma volume and platelet count before and after TAE (mean \pm $\mathrm{SD}, n=6)$.

\begin{tabular}{lcc}
\hline Time & $\begin{array}{c}\text { Hemangioma } \\
\text { maximal diameter }(\mathbf{c m})\end{array}$ & Platelet count $(\times \mathbf{1 0} \mathbf{9} \mathbf{L})$ \\
\hline Pre-TAE & $8.1 \pm 2.9$ & $20.0(8.0,30.0)$ \\
Post-TAE & $6.3 \pm 2.8$ & $255.0(200.0,280.0)$ \\
$p$-value & $<0.001$ & $<0.001$
\end{tabular}

TAE, transarterial embolization.

KMS remains unknown, and long-term follow-up is important for clinicians.

\section{CONCLUSION}

KMS is a rapidly progressing vascular lesion complicated with consumptive coagulopathy. Early effective treatment is necessary to prevent associated morbidities. In KMS patients, TAE is a safe and effective alternative therapy and may result in a good prognosis if available. We suggest that patients with KMS can be treated with TAE initially if the hospital has this technology. Our study may be limited by its single-centered, retrospective nature and the small sample size, but we would like to share our successful experience.

\section{DATA AVAILABILITY STATEMENT}

The original contributions presented in the study are included in the article/supplementary material, further inquiries can be directed to the corresponding author/s.

\section{ETHICS STATEMENT}

The studies involving human participants were reviewed and approved by Anhui Provincial Children's Hospital, Anhui Medical University. Written informed consent to participate in this study was provided by the participants' legal guardian/next of kin. Written informed consent was obtained from the individual(s), and minor(s)' legal guardian/next of kin, for the publication of any potentially identifiable images or data included in this article. 


\section{AUTHOR CONTRIBUTIONS}

YW and LD conceptualized and designed this study and wrote the paper. SW provided study material. LD and SB contributed to

\section{REFERENCES}

1. Kasabach H, Merritt K. Capillary hemangioma with extensive purpura: report of a case. Am J Dis Child. (1940) 59:10631070. doi: 10.1001/archpedi.1940.01990160135009

2. Sarkar M, Mulliken H, Perez-Atayde R. Thrombocytopenic coagulopathy (Kasabach-Merritt phenomenon) is associated with Kaposiform hemangioendothelioma and not with common infantile hemangioma. Last Reconstr Surg. (1997) 100:1377-1386. doi: 10.1097/00006534-199711000-00001

3. Radovic SV, Kolinovic M, Ljubic D. Propranolol in the preoperative treatment of Kasabach-Merritt syndrome: a case report. J Med Case Rep. (2017) 11:308. doi: 10.1186/s13256-017-1475-0

4. O'Rafferty C, O'Regan GM, Irvine AD, Smith OP. Recent advances in the pathobiology and management of Kasabach-Merritt phenomenon. $\mathrm{Br} J$ Haematol. (2015) 171:38-51. doi: 10.1111/bjh.13557

5. Ji Y, Chen S, Yang K, Xia C, Li L. Kaposiform hemangioendothelioma: current knowledge and future perspectives. Orphanet J Rare Dis. (2020) 15:39. doi: 10.1186/s13023-020-1320-1

6. Ying H, Qiao C, Yang X. A Case Report of 2 sirolimusrelated deaths among infants with kaposiform hemangioendotheliomas. Pediatrics. (2018) 141(Suppl 5):S425-9. doi: 10.1542/peds.2016-2919

7. Yao W, Li K, Wang Z, Wang J, Ji Y, Zhou L, et al. Comparison of efficacy and safety of corticosteroid and vincristine in treating kaposiform hemangioendothelioma and tufted angioma: A multicenter prospective randomized controlled clinical trial. J Dermatol. (2021) 10:19. doi: 10.1111/1346-8138.15767

8. Tan X, Zhang J, Zhou S, Liu Z, Zhang T, Xia J. Successful management of steroid-resistant vascular tumors associated with the Kasabach-Merritt phenomenon using sirolimus. J Dermatol.. (2018) 45:580-83. doi: 10.1111/1346-8138.14231

9. Wang P, Zhou W, Li T. Clinical analysis of kasabach-merritt syndrome in 17 neonates. BMC Pediatrics. (2014) 14:3-7. doi: 10.1186/1471-2431-14-146

10. Brill R, Uller W, Huf V, Muller-Wille R, Schmid I, Pohl A, et al. Additive value of transarterial embolization to systemic sirolimus treatment in kaposiform hemangioendothelioma. Int J Cancer. (2021) 148:234551. doi: 10.1002/ijc.33406

11. Wang Y-H, Dai L-Y, Wang L-L. Clinical features of Kasabach-Merritt syndrome: an analysis of 16 neonates. Chinese J Contemporary Pediatrics. (2021) 23:696-701. doi: 10.7499/j.issn.1008-8830.2103146

12. Guo L, Wu C, Song D, Wang L, Li J, Sun J, et al. Transcatheter Arterial Sclerosing Embolization for the Treatment of Giant Propranolol-Resistant Infantile Hemangiomas in the Parotid Region. J Vascul Intervent Radiol. JVIR. (2021) 32:293-8. doi: 10.1016/j.jvir.2020.09.029

13. Lindberg U, Svensson L, Hellmark T, Segelmark M, Shannon O. Increased platelet activation occurs in cystic fibrosis patients and correlates to clinical status. Thrombosis Res. (2018) 162:32-7. doi: 10.1016/j.thromres.2017.12.012 manuscript revision/review. LW was the attending physician. JZ contributed to data analysis and interpretation. PZ contributed to literature research. All authors contributed to the article and approved the submitted version.
14. Schmid I, Klenk AK, Sparber-Sauer M, Koscielniak E, Maxwell R, Haberle B. Kaposiform hemangioendothelioma in children: a benign vascular tumor with multiple treatment options. World J Pediatrics: WJP. (2018) 14:3229. doi: 10.1007/s12519-018-0171-5

15. Akhlaghpoor S, Torkian P, Golzarian J. transarterial bleomycinlipiodol embolization (B/LE) for symptomatic giant hepatic hemangioma. Cardiovascul Intervent Radiol. (2018) 41:16741682. doi: 10.1007/s00270-018-2010-4

16. Yamamoto T, Kawarada Y, Yano T, 00. Spontaneous rupture of hemangioma of the liver: treatment with transcatheter hepatic arterial embolization. Am J Gastroenterol. (1991) 86:1645-649.

17. He Y, Lan Y, Liu Y, Yu H, Han Z, Li X, et al. Pingyangmycin and bleomycin share the same cytotoxicity pathway. Molecules. (2016) 21:722. doi: $10.3390 /$ molecules 21070862

18. Li Y, Jia Y, Li S, Wang W, Wang Z, Wang Y, et al. Transarterial chemoembolization of giant liver haemangioma: a multicenter study with 836 cases. Cell Biochemistr Biophy. (2015) 73:469-72. doi: 10.1007/s12013-015-0680-y

19. Jin S, Shi X-J, Sun X-D. Sclerosing cholangitis secondary to bleomycin-iodinated embolization for liver hemangioma. (2014) 46:17680-5. doi: 10.3748/wjg.v20.i46.17680

20. Vaidya S, Tozer KR, Chen J. An overview of embolic agents. Semin Intervent Radiol. (2008) 25:204-15. doi: 10.1055/s-0028-1085930

21. Huang Y-D, Li P, Tong X. Effects of bleomycin A5 on caspase-3, P53, bcl2 expression and telomerase activity in vascular endothelial cells. Indian $J$ Pharmacol. (2015) 47(1):55. doi: 10.4103/0253-7613.150337

22. Bennett J, Reich S. Drugs five years later: bleomycin. Ann Intern Med. (1979) 90:945-8. doi: 10.7326/0003-4819-90-6-945

Conflict of Interest: The authors declare that the research was conducted in the absence of any commercial or financial relationships that could be construed as a potential conflict of interest.

Publisher's Note: All claims expressed in this article are solely those of the authors and do not necessarily represent those of their affiliated organizations, or those of the publisher, the editors and the reviewers. Any product that may be evaluated in this article, or claim that may be made by its manufacturer, is not guaranteed or endorsed by the publisher.

Copyright (๑) 2021 Wang, Wang, Wang, Bi, Zhang, Zha and Dai. This is an openaccess article distributed under the terms of the Creative Commons Attribution License (CC BY). The use, distribution or reproduction in other forums is permitted, provided the original author(s) and the copyright owner(s) are credited and that the original publication in this journal is cited, in accordance with accepted academic practice. No use, distribution or reproduction is permitted which does not comply with these terms. 